\title{
Is LOE test useful to recognize LCA insufficiency?
}

\author{
Giuseppe Laurà
}

Received: 28 October 2013/Accepted: 27 December 2013/Published online: 31 January 2014

(C) The Author(s) 2014. This article is published with open access at Springerlink.com

\section{Dear Sir,}

"I read the article "The loss of extension test (LOE test): a new clinical sign for the anterior cruciate ligament insufficient knee" by Salvi et al. [1]", and I think all that is practiced and described could be scarcely suitable for the diagnosis of ACL tear.

I completely agree with the AA on the validity of the knee joint extension maneuver (recurvatum test) as an initial clinical approach in order to test the ACL, but I retain totally arbitrary the conclusion that an ACL lesion or insufficiency may be inferred from a lack of passive knee extension, that we can notice in other articular pathologies, such as meniscal tears, loose bodies, etc, that may induce a mechanical or reflex limitation of extension.

But it is quite true and verified by my personal and other authors' experience that the mentioned maneuver, the extension test, in the presence of an ACL lesion, reveals a unilateral recurvatum [2-6], not specific to that lesion, that must be validated by the Lachman test and by functional testing.

Should it be disputed that the recurvatum could be attributed to a concomitant postero-lateral rotator instability that is also examined with the external-rotation (E. R.) recurvatum test of Hughston, it may be demonstrated by lifting the extremity by the great toe, thus causing excess external rotation and recurvatum which appears as increased tibia vara.

This test is quite different from true recurvatum in neutral rotation, which I am referring to.

G. Laurà $(\bowtie)$

Knee Surgery Department, Istituto Clinico Città Studi, Milan, Italy

e-mail: giuseppe.laura42@gmail.com
In view of the sharp contrast of views on the matter between article authors and me, I retain that my observation might be useful to launch a debate among the Journal readers.

\section{Conflict of interest None.}

Open Access This article is distributed under the terms of the Creative Commons Attribution License which permits any use, distribution, and reproduction in any medium, provided the original author(s) and the source are credited.

\section{References}

1. Salvi M, Caputo F, Piu G et al (2013) The loss of extension test (LOE test): a new clinical sign for the anterior cruciate ligament insufficient knee. J Orthop Traumatol 14(3):185-191

2. Hughston JC, Andrews JR, Mervin JC, Moschi A (1976) Classification of knee ligament instability. Part 1 The medial compartment and cruciate ligaments. J Bone J Surg 58A(2): 159-172 (p.172 conclusions 7)

3. Furman W, Marshal JL, Girgis FG (1976) The anterior cruciate ligament a functional analysis based on postmortem studies. J Bone J Surg 58A(2):179-185

4. Al-Dury Z (1992) Relation of the fibular head sign to other signs of anterior cruciate ligament insufficiency. Clin Orthop RR 275:220-225

5. Meyer EG, Bauwer TG, Haut RC (2011) Pure passive hyperextensions of the human cadaver knee generate simultaneous bicruciate ligament rupture. J Biomech Eng 133(1):01012

6. Bousquet G, Le Beguec P, Girardin P (1991) Les laxites chroniques du genou Medsi. McGraw-Hill, Paris 